\title{
UN ENSAYO DE LA RAZÓN. NACIÓN Y LITERATURA EN EL ÁMBITO REPUBLICANO CUBANO
}

\section{AN ESSAY OF THE REASON. NATION AND LITERATURE IN THE CUBAN REPUBLICAN FIELD}

\author{
Jeisil Aguilar Santos*
}

\section{RESUMEN}

En este artículo se realiza un acercamiento a la relación entre categorías sociales importantes en los estudios de pensamiento actuales. El objetivo es brindar una panorámica de la relación nacionalismo-cultura en el ámbito de la República cubana. Se hace énfasis en la obra de los origenistas, por ser una de las generaciones de mayor alcance en el pensamiento y la literatura de la etapa.

PALABRAS CLAVE: CUBA * CULTURA * LITERATURA * REPÚBLICA * NACIÓN

\section{ABSTRACT}

In this article is made an approach to the relationship between social categories important in studies of current thinking. The aim is to provide an overview of the relationship nationalism-culture in the area of the Cuban Republic. Emphasis is placed on the work of the origenists, being one of the most far-reaching generations in thought and literature of the stage.

KEYWORDS: CUBA * CULTURE * LITERATURE * REPUBLIC * NATION

Departamento de Estudios Socioculturales, Universidad Central "Marta Abreu" de Las Villas, Cuba. jeisil@uclv.edu.cu 
En los estudios de pensamiento como en el arte, existe una tendencia a presentar la cubanidad como una esencia incuestionable y perdurable, diferenciada de lo español en el caso colonial $y$ de lo norteamericano en el caso neocolonial. Esta "esencia" se presenta metafórica o simbólicamente en consonancia con el fuerte contenido ideológico, aparentemente consiente, de estos discursos. Sin embargo, otros intelectuales mantienen la idea de la esencialidad desde un análisis en la relación contextual. Tal es el caso de Cintio Vitier (1970), quién, en Lo cubano en la poesía, concibe "la cubanidad" o "lo cubano" como el resultado de un complejo proceso de toma de conciencia de "lo que más genuinamente nos expresa en cada instante" por el que la identidad no puede verse como expresión de una realidad previamente constituida, al margen de los discursos que la articulan.

En todo caso, la percepción sobre "lo nacional" esta permeada de artificios políticos de acuerdo al grupo que la maneje (¿es en su totalidad un artificio político?). Esto responde al hecho de que cada concepción ideológica surge en respuesta a necesidades no satisfechas por las promesas ideológicas imperantes. Cada concepción ideológica se establece como una construcción metafórica aparentemente inconsciente e inconsulta. De esta manera, lo cubano como identidad y las concepciones alrededor de esta, son el producto de la invención alrededor de lo nacional (generalmente como tradición o imaginario común) puesta al servicio de proyectos específicos.

La literatura sostiene o participa de la conformación nacional. Ejemplo de lo anterior es la fundación de la República de las Letras Cubanas, durante el siglo xix, conformada por un grupo de intelectuales cubanos, entre los que se encuentra a Varela, Luz, Saco y Del Monte. Esta no es otra cosa que la estructuración de un campo intelectual alternativo, fundamentalmente literario, definido como autónomo que propiciaría ciertos niveles de independencia e influencia cultural y política. Sus enunciados estaban abocados a la conformación de un proyecto llamado por la Dra. Irma Llorens, "Patriotismo cauteloso" (1998: 20), centrado en declarar una posibilidad alternativa al centralismo colonial.

Estos "nacionalistas moderados", ante la situación social de la colonia cubana, entablan un debate derivado en una lucha de opiniones que disfraza la lucha por el poder en el escenario cultural cubano. El poder simbólico que este grupo de intelectuales codicia en el campo de la cultura, refiere en la práctica, el poder de elegir y dirigir intelectualmente al país, lo que puede ser concebido como un intento de alcanzar mayor autonomía política. Se dan a la tarea de validar su posición ante a la autonomía que pretenden; crean instituciones alternativas al campo intelectual oficial, se dedican a la promoción de su oficio desde mecanismos de propaganda que contienen como centro la polarización, dada en la superioridad ética de ellos con respecto a la corrupción de los otros. Además, utilizan como mecanismo de cohesión y promoción para lograr la verosimilitud, un discurso articulado desde la historia que tiene como escudo una "política de desinterés", donde lo único importante son los bienes abstractos. Este es un discurso que se apoya constantemente en postulados alrededor de la concepción "Patria".

La lógica del pensamiento indica que ningún hecho, sin importar la categoría en que se incluya, escapa a su contexto específico. El pensamiento cultural cubano está permeado de lugares comunes al respecto. Por esta razón, surge la pregunta: ¿qué elementos son comunes al pensamiento cubano de todos los tiempos? La respuesta a esta interrogante puede resultar escabrosa si se tiene en cuenta la heterogeneidad que ha caracterizado a la conformación nacional cubana, la cual cuestiona la existencia de una ideología cubana a la vez se pregunta: ¿cómo se conforma esta ideología?

El autor Fernando Martínez Heredia, en la presentación del nro 7 de la Revista $\mathrm{Ca}$ libán, sitúa al nacionalismo como la corriente ideológica más frecuente en el pensamiento cubano entre la década del 20 y el año 58 del siglo xx en Cuba:

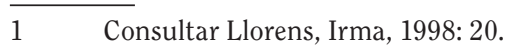


Ni el anarquismo y ni su fe organizativa sindicalista tan importante en la historia de las luchas por la justicia social del primer cuarto del siglo xx, ni el comunismo, fundado al calor de la Internacional Comunista, que fue tan influyente en la década siguiente, lograron comprender bien ese legado y mucho menos declararse con éxito los herederos de él y los destinados a conducir la realización del proyecto nacional (2010).

La formación de lo que se podría llamar una "ideología cubana" comienza desde la colonia y tiene en José Martí uno de sus principales exponentes. El Apóstol, aun cuando lógicamente, no escapa a las limitaciones de su contexto, superó considerablemente todo el pensamiento de su época, lo que lo convierte en objeto de análisis para todo aquel que pretenda estudiar el pensamiento y especialmente, aquel referido a la nacionalidad cubana.

Sería infundado pretender que recae en Martí todo el conocimiento y aportes ideológicos de la época. Al pensamiento Martiano aportaron todos los pensadores anteriores $y$ aquellos con los que coexistió. Mucha de la obra de este se puede encontrar en las publicaciones de la época, distribuida fundamentalmente en discursos, artículos y ensayos. En el ideario martiano contenido en estas publicaciones, se percibe un desarrollo ascendente, en lo referente a la comprensión de los problemas nacionales y latinoamericanos en general.

En la investigación realizada por la Dra. Mely González Aróstegui en La Cultura de la Resistencia en el pensamiento político de la intelectualidad cubana en las dos primeras décadas del siglo xx en Cuba se referencia a esta evolución.

En un primer momento, esencialmente liberal, Martí no comprende a cabalidad el papel de la clase obrera y de la lucha de clases, considerando que la solución de los problemas está solo en la distribución de la tierra y en la instrucción. La identificación del pensamiento martiano con el liberalismo responde a las aspiraciones, que tenían la mayoría de los pensadores de la época, liberales radicales, de construir una república, cuyo modelo ideal en materia de democracia, se encontraba en lo construido por Estados Unidos.

En una segunda etapa supera el liberalismo, proponiendo, luego de comprender que el problema agrario era solo el punto de partida para la solución de los males sociales, una nacionalización de la tierra. Este programa posee limitaciones pero sin dudas es un paso progresista dentro del pensamiento de la época. Sus trabajos posteriores a 1887 , principalmente Nuestra América, son superiores en tanto comprenden una visión de la realidad latinoamericana desde perspectivas más críticas y abarcadoras. A partir de este momento, el pensamiento martiano evidencia mayor claridad en torno al papel y al peligro que constituye el imperialismo como elemento externo, haciendo mención además a los factores internos que permiten tal penetración (González, 2000).

El ideario martiano sirve de base para el pensamiento republicano. El antinjerencismo, como el antiimperialismo de corte liberal positivista asumen posturas provenientes del pensamiento de José Martí, anterior a la década del 80 , caracterizado por ideas independentistas y antinjerencistas, marcadas por el liberalismo en general. El antiimperialismo de corte marxista, que cobra auge durante la década del $20 y$ hasta finales de la revolución del 30, también tiene un precedente en la figura del Apóstol, sobre todo en la obra posterior a la década del 80 , donde ocurre un viraje hacia un antiimperialismo democrático, centrado en la universalidad del problema de la dominación del imperialismo. Sin embargo, no es el antiimperialismo la ideología de principios del siglo xx, sino nuevamente el reformismo, el liberalismo y el antinjerencismo en sus múltiples variantes. Este hecho constituye, sin dudas, un retroceso en el proceso evolutivo que venía gestándose en la colonia y que tiene como exponente fundamental el ideario martiano. Esta circunstancia esta dada por múltiples factores.

La frustración del proyecto martiano con el advenimiento de la República trajo consigo un repliegue en la madurez del pensamiento cubano. Ante la injerencia norteamericana, la pequeña burguesía, que no era esencialmente 
nacionalista pero que sí poseía un pensamiento liberal muy enraizado, mantuvo posiciones que fueron desde el acomodamiento hasta la crítica a la Enmienda Platt. Pocos pensadores entendieron a cabalidad el problema de la injerencia económica y muchos menos el significado de la penetración del imperialismo.

$\mathrm{El}$ antinjerencismo, durante estos primeros años, transita por varias posiciones: partidarios de la derogación del la Enmienda Platt, partidarios de una reformulación de la misma, hasta defensores de "la virtud doméstica contra la injerencia yanqui" 2 . Esta última posición se mantiene constante durante la mayor parte de la República desde diversas consignas, abogadas de la civilidad frente a la corrupción. Entre estas se encuentra la premisa positivista "orden y progreso" adoptada por la burguesía cubana en el afán de construir un capitalismo independiente.

Si bien, el antinjerencismo está estrechamente ligado a la posición frente a la Enmienda Platt como elemento rector de la injerencia norteamericana en la isla, no está limitado a esta. Definir a un pensador como antinjerencista amerita un análisis más detenido, que desborde el hecho del voto frente a este acápite.

El movimiento contra la injerencia, liderado por Manuel Sanguily, Enrique José Varona, Salvador Cisneros Betancourt, Carlos de Velasco, Eliseo Gilberga y Márquez Sterling, como los más destacados, aun cuando rechaza la intervención y la penetración norteamericana, lo hace fundamentalmente por un problema ético, previendo el peligro que para Cuba, como Nación, constituye esta injerencia. El movimiento antinjerencista en la etapa, no rebasa el liberalismo como corriente ideológica $y$ posee un marcado sentido nacionalista, refrendado en la mayoría de los casos en la producción artística.

Este sentimiento hacia la Nación, vista no solo como una entidad política soberana, sino también como "auténtica comunidad imaginada"3, siendo diverso, se mantiene como

$2 \quad$ Frase acuñada por Márquez Sterling en un artículo del mismo nombre.

3 Término utilizado por Abreu Arcia, 2007: 194. una constante en el pensamiento cubano, en la forma del patriotismo, del antinjerencismo $y$ del antiimperialismo, liberal o radical. En la divulgación de este pensamiento desempeñaron un papel fundamental las publicaciones seriadas de la etapa, Cuba Contemporánea, Cuba y América, Social, entre otras. Fueron esencialmente, órganos de difusión del pensamiento de la época, tanto del antinjerencismo como del antiimperialismo décadas más tarde.

El nacionalismo cubano, expresado en estas "ciudades letradas", poseía una gran heterogeneidad según el sector o el grupo que lo adoptara, por lo que algunos autores han preferido hablar de "nacionalismos" cubanos. Durante las dos primeras décadas republicanas, esta corriente se enfocó fundamentalmente hacia el problema de la Enmienda Platt y del injerencismo político norteamericano. Pocos pensadores entendieron a cabalidad la importancia de una construcción nacional propia y la relación de esta con la edificación de una economía independiente.

Al mismo tiempo, el antiimperialismo de corte liberal positivista coexiste junto al antinjerencismo y el nacionalismo en los primeros 20 años. Esta corriente ideológica, pese a sus limitaciones, constituye un paso de avance respecto al anti-intervencionismo y al antinjerencismo de los primeros años. Entre las figuras que profesan esta corriente a inicios de la República, se pueden encontrar a Varona, Cisneros, Juan Gualberto y Sanguily. Este movimiento reconoce el peligro de la absorción económica de Cuba por Estados Unidos pero no comprende al imperialismo en su esencia. Los intelectuales cubanos de la etapa, en general, son capaces de vislumbrar los efectos externos del sistema, sin llegar a análisis más profundos. Esta incomprensión está dada fundamentalmente por el desconocimiento del marxismo y del imperialismo en su esencia.

Entender el imperialismo únicamente por sus manifestaciones externas significa no comprenderlo. La expresión política no es más que una manifestación externa de la necesidad interna del

4 Término acuñado por Ángel Rama, 1984. 
monopolio de desarrollarse dominando nuevos mercados por la saturación de los propios (González, 2000: 97).

Una de las limitaciones fundamentales de esta corriente, expresada por los pensadores antes mencionados, es la incomprensión alrededor de los efectos reales de la penetración económica.

La consigna antes citada: "contra la injerencia extraña, la virtud doméstica”, es muestra fehaciente de que los pensadores de la época coincidían en que lo necesario para solucionar el problema nacional cubano estaba en meras reformas cívicas y éticas. Márquez Sterling, autor de la anterior sentencia, de un pensamiento profundamente nacionalista, incapaz de comprender el peligro real de la penetración capitalista, entiende como única solución posible el fortalecimiento de la nacionalidad desde la consolidación de valores propios, de ahí la frase: "cubanizar a Cuba". Por otra parte, Varona - uno de los pensadores más lúcidos de principios del siglo xx cubano- coincide en que los cambios respecto a la situación de Cuba deben darse en el orden interno, no en las relaciones de Cuba con los Estados Unidos.

El año 1923 marca un momento significativo en el desarrollo ideológico cubano. Las contradicciones inherentes a la estructura subdesarrollada $y$ dependiente de la sociedad neocolonial, se han puesto de manifiesto con tanta agudeza, que por primera vez se hace evidente la necesidad de un cambio en todos los aspectos de la vida del país. La mayoría de las críticas a la situación imperante provienen de gente culta de la clase media, sobre todo de los intelectuales que en la década anterior de manera muy sutil vislumbraban las circunstancias de la isla. Se producen importantes hechos de rebeldía, mejor organizados y con un propósito mejor definido: la protesta de los Trece, el Movimiento de Reforma Universitaria, la fundación del primer Partido Comunista, el Congreso de mujeres, la fundación de la Universidad Popular José Martí. Adyacente a esto se comienza a producir un arte con atisbos propios de la nacionalidad cubana. Este movimiento de renovación es nombrado vanguardismo y representa de manera explícita los cambios en el orden ideológico que acontecían en la isla.

La vanguardia es un rompimiento con los dogmas del academicismo, una forma de plantear el desacuerdo con el régimen de normas imperantes, no solo desde aspectos artísticos sino desde el punto de vista ideológico, porque la libertad expresiva y la valentía expresiva artística solo se da cuando se adquiere conciencia de la discrepancia. Esta rebeldía artística no es más que reflejo de la rebeldía social, síntoma del colapso del conjunto de valores que hasta entonces se habían tenido como válidos. La vanguardia artística en la etapa se centra fundamentalmente en destacar la nacionalidad cubana, lo que demuestra, más que una maduración artística es una maduración ideológica de la intelectualidad republicana.

En el quehacer contra la desnacionalización cubana debe destacarse la labor realizada por el minorismo y frente a este, Rubén Martínez Villena; el papel de los estudiantes universitarios, con Mella a la cabeza; así como la labor de revistas y publicaciones periódicas entre las que destaca Social (en su última etapa), De Avance, Atuei y más tarde, en la década del 40, Orígenes.

Dos hechos fundamentales caracterizan esta etapa: el comienzo de la crisis del orden neocolonial y el vigoroso despertar de la conciencia de capas considerables del pueblo. Emergen a la escena nacional un número importante de organizaciones de corte marxista radical, reflejo de un desarrollo ascendente en cuanto a la cultura política de los organizadores de la guerra. La intelectualidad, tímida hasta entonces, se incorpora a la lucha, desde la crítica abierta refrendada sobre todo en las publicaciones de la etapa. En Cuba Contemporánea, Social y Revista de Avance; en las tertulias, mítines y protestas; en las novelas, poemarios, la plástica vanguardista y en el arte en general, comienza a ser recreada la realidad social de manera más explícita.

Movimientos y publicaciones que tenían como objetivo la producción artística y se planteaban desligadas de la política, manifiestan un giro considerable convirtiéndose en protagonistas de la escena cubana durante la década 
crítica. Tal es el caso de Revista de Avance, que no solo auspicia la primera exposición de Arte Nuevo, durante el año 1927, sino que supera su primer objetivo, exclusivamente artístico, conmoviéndose por las urgencias sociales en que nace $y$ en esta se reflejan, de manera inevitable, convirtiéndola en testigo de una época sin dudas convulsa y de profundos cambios ideológicos (Marinello, 1973).

Los artículos publicados en la Revista de Avance, revelan posturas antiimperialistas, enmarcadas fundamentalmente en críticas a las imposiciones y atropellos llevados a cabo en Cuba, pero sobre todo en países latinoamericanos por los gobiernos de turno, mediados por los Estados Unidos. En la sección "Directrices", ofrecen criterios sobre temas $y$ acontecimientos culturales, artísticos o políticos de Cuba y otros países. El primer comentario realizado en esta sección, expone los propósitos de la revista, pero en su último número se hace referencia a la situación de crueldad en que estaba sumido el país: ¿a dónde vamos, a dónde queremos ir con esta política cuya crueldad sólo resulta levemente atenuada junto a su torpeza? (Revista de Avance, setiembre de 1930).

Este último número incluye una protesta en contra de la disolución de la manifestación del 30 de setiembre, en la que muere Rafael Trejo: como consecuencia de esta dragonada [dice una nota de última hora], un estudiante acaba de morir al escribirse estas líneas...

El hecho de que esta revista, nacida con el objetivo de expresar el movimiento artístico, muriera junto a un líder estudiantil, aun cuando parece una metáfora lírica, ofrece en cierta medida, un retrato de la transformación que hacia el interior de la misma se había configurado. Una transformación que es testigo de lo que estaba ocurriendo con los intelectuales cubanos de la etapa y que tiene en Julio Antonio Mella y en la revolución del 30, un exponente máximo.

A partir de este momento, comienza una etapa nueva en el orden ideológico, que le gana espacio, según el investigador Fernando Martínez Heredia, al liberalismo, entre otras formas ideológicas propias de las etapas anteriores, dígase el anarquismo y el anarcosindicalismo.
Durante la revolución del 30, el antiimperialismo se convierte en la base de la cultura cubana de liberación, siendo la única ideología posible, expresada en diversos matices: el radical con el marxismo y el reformista-conservador con el nacionalismo.

La llegada al antiimperialismo como todo proceso social, dependió de que las condiciones históricas e ideológicas lo permitieran. La crisis económica de los años 20, la decepción de los intelectuales y pequeña burguesía en general, ante la no solución de los problemas cubanos, la constante intromisión de los Estados Unidos, la maduración de una vanguardia artística dispuesta a romper con cánones coloniales, el resurgimiento del ideario martiano, el auge de publicaciones centradas en problemas universales y en universalizar problemas nacionales, entre otras cuestiones, son los detonantes de la radicalidad del pensamiento luego de la década crítica.

El radicalismo en la Revolución del 30 asumió en el antiimperialismo y el socialismo, dos nuevas dimensiones respecto al patriotismo nacionalista y la ideología mambisa de los radicales previos (Martínez, 2007).

En este punto se había comprendido que la transformación que necesitaba el país no podía darse en el orden ético o cívico solamente, que los cambios en Cuba debían ser cambios de sistema, imposibles sin desprenderse de la dependencia económica de Estados Unidos. Esta certeza fue acompañada de algunos factores externos entre los que destacan la agudización de las relaciones entre Cuba $y$ Estados Unidos, la influencia de la revolución de octubre, la revolución mexicana y la reforma universitaria de Argentina.

El pensamiento cubano durante la revolución del 30 , especialmente en la figura de Julio Antonio Mella, realiza un vuelco considerable en la comprensión del problema nacional. Esta comprensión le permitió a Mella estar en el centro del movimiento obrero, estudiantil e intelectual. No solo a través de la crítica certera sino además, en la fundación y organización de disímiles organizaciones, entendiendo que la revolución provendría definitivamente de la sociedad civil. 
Mella retoma y revalida la radicalidad como asunto concerniente a la intelectualidad cubana, desde la conciencia crítica y la asunción de la ética. En Glosas del pensamiento martiano (Mella, 1975), el joven revolucionario demuestra una intención integradora que permite encontrar puntos de contacto entre el pensamiento martiano y el marxismo. Esta actitud evidencia un fuerte compromiso con la constitución de un proyecto nacional cubano, que encuentra en el Apóstol una formulación definitiva.

Mella no fue el único pensador de la revolución del 30 en el que se unen pensamiento intelectual y compromiso político, claridad y radicalidad ideológica. Guiteras, Villena y Roa, fueron también pensadores importantes en este período. El radicalismo de Antonio Guiteras durante el gobierno de los cien días, el papel de Villena ante el minorismo y la conversión del discurso estético en un discurso político tienen un papel fundamental durante las décadas $20 y$ 30 del siglo xx cubano.

Con la derrota de la revolución del 30 , sucede en Cuba un retroceso en el orden ideológico que rompe con la evolución que se venía gestando en el pensamiento cubano hacia soluciones radicales del problema nacional. Este repliegue está mediado por la conformación de una ideología que se desvía de la radicalidad de la revolución anterior para tener como centro nuevamente las reformas y el nacionalismo. En este proceso ocupa un papel fundamental la constitución del 40.

La constitución del 40, considerada una de las más avanzadas y progresistas de su momento, reguló los derechos de los trabajadores permitiendo la semana de 44 horas, el descanso de un mes por cada once de trabajo, la licencia de maternidad pagada de seis semanas antes del parto y seis después del alumbramiento, la igualdad de remuneración de hombres y mujeres, la prohibición de disolver sindicatos sin sentencia de un Tribunal de Justicia, las oportunidades de trabajo para todos, entre otros. Es evidente que aunque la mayoría de estas reformas nunca fueron efectivas, significaron una esperanza para los cubanos del momento. Un análisis de la significación cultural e ideológica de esta constitución no debe alejarse de su contexto específico, sobre todo en este caso, en que la trascendencia del hecho rebasa su contenido específico convirtiéndose en referente actual en el orden político-ideológico.

Las promesas realizadas por esta constituyente, unidas a las características propias de una etapa prorevolucionaria $y$ al resurgimiento del reformismo ético como centro del pensamiento cubano, constituyeron el caldo de cultivo perfecto para el cambio ideológico acontecido luego del 40 y que se sostuvó hasta la década del 50.

A pesar de los fracasos, el proceso que dio a luz a la Constitución del 40 , constituye un síntoma de cambio importante. Al respecto de lo anterior, Julio César Guanche plantea:

Fracasaron los intentos organizativos de unidad, a partir de 1935; pero comunistas, auténticos, liberales, conservadores y todo el arco político nacional se sentó a solventar sus intereses en 1940, dentro de una Asamblea Constituyente. Resultado de esa conciliación nacional, una Constitución - la más avanzada de su época en el continente americanovio la luz (2004: 18).

La revolución del 30 constituye un punto de partida para cambios importantes en la concepción alrededor del "problema nacional". Aun cuando la burguesía se vuelve al nacionalismo, luego del 30, las concepciones sobre "lo nacional" cobran matices distintos que derivan en retomar elementos de la cultura cubana anterior a la República. Se retoma el ideario martiano, se crean instituciones que aluden a una Cuba Nueva ${ }^{5}$ y se incorporan las corrientes de pensamiento más modernas de la época. El nacionalismo posterior a los años 30 no se enfoca en el antinjerencismo sino en la solución de los conflictos cubanos desde soluciones internas, ajenas a la relación con Estados Unidos. Durante esta etapa, la diversidad de formas actuantes no permite una clasificación estrecha para la

$5 \quad$ Esto se fundamenta en la creación de organizaciones como la Joven Cuba en 1934 por Antonio Guiteras 
ideología cubana, pero es fácil distinguir que la Revolución del 30, en una reinterpretación dialéctica de la frase, "se fue a bolina".

En los años 40 y 50, las reformas fueron el boleto más usado por los gobiernos y organizaciones de turno, la radicalidad quedó olvidada y fue esta situación de "pequeñas dosis", lo que condujo para la inminencia del triunfo revolucionario en el 59. Estos cambios, aunque de orden ideológico, son recreados de manera clara en la producción estética e intelectual de la época, principalmente en aquella refrendada en publicaciones seriadas y periódicas. El surgimiento de Revistas como Orígenes y Nuestro Tiempo, los cambios al interior de Bohemia, son reflejo de la situación político-social del país.

En esta etapa, en que se recurre nuevamente a la reforma como mecanismo para solventar las debilidades políticas e ideológicas cubanas, el nacionalismo se mantiene como una constante, desde el análisis del problema nacional hasta el reflejo o recreo de "lo nacional", no como contenido político, sino como asunto del arte, especialmente de la literatura. El nacionalismo en la literatura cubana se encarga fundamentalmente de la sistematización de la continuidad cultural nacional, de la fundación de un discurso nacional desde la literatura, de la legitimación de lo nuevo y la revitalización de lo anterior como sostén convertido en tradición artística a la vez que ideológica.

Esta es una tendencia común en los intelectuales, no solo cubanos, contentiva del intento de construir una tradición literaria o artística en general, que contribuya en una concepción nacional, dentro del imaginario cultural, que a su vez sostenga la construcción de la Nación, políticamente hablando. En pocas palabras, la creación o (re)creación de una tradición literaria "digna" que se constituya como universal, permite que la nacionalidad, en este caso, la cubana, ante lo ajeno, emerja como natural incuestionable.

En el caso cubano, esta búsqueda devenida legitimación, gira alrededor de José Martí como universal, en que al decir de los origenistas, culmina el desarrollo de la cultura e historia cubanas. Respecto a lo anterior, Lezama plantea: ...el siglo pasado ofrece una tradición poética desde Heredia hasta Martí y una tradición pedagógica desde Luz y Caballero hasta Martí y vemos siempre a Martí en el centro de estas tradiciones... Martí fue el que en realidad dio a los cubanos el sentido de la toma de posesión de lo cubano por lo cubano (1993: 167-168).

En otro texto reitera: "la dimensión imponente que dominó José Martí no ha sido, no superada, si siquiera igualada y es fácil que no lo sea nunca" (Lezama, 1993: 89). Afirmaciones como la anterior, se refieren a la dimensión universal de Martí, fuera de su poesía esencial, que nos enseña como debe vivir y morir un cubano (Lezama, 1992: 132).

En el texto La Expresión americana, específicamente en los ensayos "El Romanticismo y el hecho americano" y "Nacimiento de la expresión criolla", Lezama hace referencia a la obra de José Martí y José Maria Heredia como expresiones y máximos exponentes de lo cubano. De esta forma:

En estas mezclas de alegre rebelión para encontrar el buen refrán, cómo no recordar el criollismo de José María Heredia, para que el sol alce su frente al encanto de su fama o el yo alzare el mundo de José Martí. Ambas son formas de pretender para ayudar, ambas criollísimas (2010: 47).

José Lezama Lima, entre otros intelectuales, se alista en la conformación de una genealogía de la tradición literaria cubana a la que se afilia como sostén de la nacionalidad. La referencia constante a la obra de José Martí comienza desde muy temprano en Lezama, desde las páginas del Diario de la Marina, en que este autor tenía una columna habitual ${ }^{6}$, hasta el poema descubierto por Cintio: La casa

\footnotetext{
$6 \quad$ Los textos contenidos en esta columna se compilan en Espinosa Domínguez, Carlos (Comp.). José Lezama Lima. Revelaciones de mi fiel Habana. Ediciones Unión, 2010.
} 
del Alibi 7 . En el texto "Para Llegar a Orígenes", editado por Letras Cubanas en 1994, Cintio Vitier, fervoroso martiano y origenista por derecho propio, dedica unas páginas al análisis de este poema en que el autor de Opiano Licario declara su idolatría por el Apóstol cubano. De tal forma, para Lezama: "José Martí fue... la última casa del alibí". Es importante entender, a partir del significado de este último término, la trascendencia que otorga este autor a la figura martiana, en tanto creador universal ${ }^{8}$ que contiene en sí los fundamentos de toda la historia cubana como "el estado místico donde la imaginación puede engendrar el sucedido $y$ cada hecho se transforma en el espejo de los enigmas" (Lezama, 1953: 3). En las páginas de Orígenes Lezama comenta de Martí:

...su permanencia indescifrada continúa en sus inmensos memoriales dirigidos a un rey secuestrado: la hipóstasis o sustantivización de los alegres misterios de su pueblo. En sus cartas nos describe para su primera secularidad una tierra intocada, símbolos que aun no hemos sabido descifrar como operantes de las fuerzas históricas (1953: 3).

Los origenistas ven en José Martí el nacimiento y clímax de la cultura cubana, no solo desde su arsenal poético (re) fundador del idioma, sino desde la posesión, de un poder que se entiende mítico, ancestral e indisputable. En este otorgamiento, legitimando la figura martiana, no solo se legitima su discurso (universal pero defensor de lo cubano) sino se ensaya un discurso profundamente trascendentalista, abarcador de lo cubano como esencia universal. En las páginas de Las Coordenadas Habaneras (Espinosa, 2010) el líder de Verbum, Espuela de Plata, Parecía y Orígenes, explica

$7 \quad$ Este poema es encontrado por Cintio Vitier entre las páginas del manuscrito del último capítulo de Paradiso. Ver en Cintio Vitier. Para llegar a Orígenes. Editorial Letras Cubanas, La Habana, Cuba. 1994: 35-48.

Es importante entender que en cuanto creador universal Lezama concibe a Martí como la figura insuperable capaz de prever y dictar con el único poder de su palabra el destino de Cuba. cómo concibe dicho poder en Martí, de tal forma que parece tornarse un ente civilizador proveedor de todas las justificaciones necesarias a la nacionalidad cubana:

Oigamos la textura del aliento de las palabras para celebrarle el nacimiento, pues el nacer de José Martí, comprendía el nacer de una forma del idioma $y$ del sacrificio, la configuración de un esplendor nuestro para las palabras y sus sobresaltos al oírlos...

Así como su aliento y su mano podían arracimar las palabras, su destino le ocupaba y comprendía con la sencillez resuelta del árbol que se sitúa en su paisaje. Cuando muere lo hace en una batalla para despedirse con misterio y hoy le celebramos la aparición, rindiéndole las gracias, seguimos tocándolo y reconociéndolo despacio para justificar el surgimiento de su germen, como si lo igualáramos a la semilla que necesita de su tierra. Pues poder justificar que su nacimiento tenía que ser entre nosotros, podría justificar de una vez la avivadora posibilidad de una historia y la solución de la forma de nuestros estilos posibles (Espinosa, 2010: 146-147)

En cierta manera, esta reinstitucionalización de la literatura cubana ${ }^{9}$ contribuye a su legitimación. A lo que a la vez legitima el discurso contenido en la misma, un discurso que desde finales de los años 20, es esencialmente nacionalista.

La obra de Cintio enmarca también un análisis alrededor de la libertad, en tanto categoría filosófica-estética, relacionada no solo con valoraciones teológicas sino con cuestionamientos sociales bastante explícitos en algunas de sus obras. Estos cuestionamientos en Vitier "han contribuido a la evolución de un concepto de praxis liberadora en un sentido dialéctico" (Marrero, 2010: 93).

9 Este término es tomado de Díaz Quiñones, 1987: 26 y ss. 
Se puede encontrar también en Cintio una recurrencia consiente al pensamiento martiano como enaltecedor de la cubanidad $y$ en tanto, sustento teórico-estético. Esta recurrencia está dada no solo en la asimilación de los referentes estéticos, morales y éticos del héroe nacional cubano, sino en la actividad de promoción relacionada a la obra de José Martí desarrollada por Cintio durante gran parte de su vida. Al respecto de lo anterior, la Dra. Marrero Fernández plantea:

La materialización del pensamiento martiano no solo se encuentra en sus textos impresos, sino además, en su labor de divulgación y de análisis de la obra de José Martí, en las ediciones de las Obras completas; en especial, en su edición crítica, en su posición antiimperialista; en sus análisis críticos sobre la perfectibilidad de la obra revolucionaria; en su colaboración en la formación de valores de la joven generación y en el fortalecimiento de la identidad nacional, la cual está centrada en la estética de la libertad (2010: 103).

Es evidente que el pensamiento alrededor de la "nación cubana" durante los últimos 20 años de la República neocolonial, está matizado por una justificación de la cubanidad fundada y fundamentada en los referentes históricos cubanos más universales, especialmente, en Martí como fundador del pensamiento político y literario cubanos. Esta búsqueda se justifica en lo que parece ser la ausencia de la nación (Alfonso, 2005) o como mínimo, la carencia de ideales nacionales acorde a las expectativas de la intelectualidad nacional, todavía vigente en los años 50 del siglo xx en Cuba.

El pensamiento intelectual nacionalista de los años 40 y 50 refiere esta ausencia constantemente a partir de un discurso de fundación o (re) fundación nacional que alude los valores patrios, la existencia de una tradición literaria digna y universal, la necesidad de defensa ante la injerencia cultural extraña, la búsqueda de soluciones en el orden de la eticidad y la urgencia de una ofensiva ante la recurrencia nociva de la crisis cultural nombrada por Mañach como "crisis de la alta cultura".

Para Jorge Mañach, un problema medular que influía en la ausencia de una nación independiente en Cuba, era la corrupción en que se encontraba la cultura cubana durante la República. Muchas veces insiste este intelectual en esta problemática, no solo en su mencionada Crisis de la alta cultura en Cuba (Mañach, 1925) sino en otros trabajos en los que se puede contar Indagaciones al Choteo. En este último refiere:

Si le pedimos, pues, al cubano medio, al cubano "de la calle", que nos diga lo que entiende por choteo, nos dará una versión simplista, pero que se acerca bastante a ser una definición porque implica lógicamente todo lo que de hecho hallamos contenido en las manifestaciones más típicas del fenómeno. El choteo — nos dirá- consiste en 'no tomar nada en serio' (Mañach, 1955).

En relación a Jorge Mañach, intelectual polémico que tuvo mucho que ver con el orden de cosas en el campo intelectual cubano de los 50, se deben atender algunas cuestiones, relacionadas al nacionalismo como a su concepción respecto al papel que una revolución nacional jugaría en la desconstrucción de la Nación cubana.

Mañach, como muchos intelectuales republicanos, no supera las características propias de la clase en que convive, independientemente de su agudeza como crítico de arte y teórico de la cultura. Este es uno de los autores que con más fuerza declara la ausencia de una Nación cubana cuando en reiterados textos se refiere a la Nación que nos falta, los hombres públicos de que carecemos y la cultura que no tenemos ${ }^{10}$, entre otros. Para Mañach, la nación es "la posesión en común de un rico legado de memorias, $y$ el consentimiento actual y el deseo de vivir juntos, la voluntad de seguir haciendo valer la herencia que se recibió indivisa" (Mañach, 1944a: 47).

10 Todas estas referencias fueron sacadas de: Alfonso López, Félix J. 2005. 47-48. 
Uno de los presupuestos más cuestionables de Mañach está en el formulado alrededor de las revoluciones sociales y su papel en torno a la formación de las naciones. En el texto $L a$ Nación y la formación Histórica presentado por este intelectual para su ingreso a la Academia de la Historia de Cuba, este formula sus principales tesis alrededor del problema nacional y los elementos que se deberían tener en cuenta en la consecuente solución de las carencias de Cuba en los años republicanos.

Mañach plantea que las revoluciones sociales, en cuanto sucesos radicales, atentan contra la integración nacional. Defiende que son los intelectuales, como grupo privilegiado y sujetos de la cultura, los encargados del diseño de la realidad, desde la educación correctamente guiada en la austeridad $y$ la decencia. Vuelve en Mañach la concepción de que solo desde lo moralmente correcto, desde la etnicidad fundada en la educación, se puede lograr la nación en Cuba. Según su concepción no está en las masas la función de guiar esta realidad sino en las minorías privilegiadas, iluminadas con la alta cultura artística (Mañach, 1944b y Alfonso, 2005).

En este texto, el autor de Indagación al choteo (Arcos, 1999) determina cuáles elementos son fundamentales para la integración nacional: general acatamiento de un número de normas y valores consagrados, culto orgulloso del pasado colectivo, observancia fiel de todos los ritos destinados a conmemorar el pasado común, respeto a los hombres, lugares y monumentos históricos, respeto a las tradiciones culturales $y$ patrimonios colectivos, respeto a los hombres públicos y a los intelectuales, disposición latente al heroísmo cívico y guerrero, avidez por la cultura.

\section{CONCLUSIONES}

Esta lista de mandamientos dictada por un intelectual que como se ha referido, es poseedor de una agudeza cultural increíble, no rebasa su circunstancia social inmediata y se torna cuestionable en un análisis incluso superficial. Una primera mirada ofrece una lista de sumisiones, que disfrazadas de respeto, impiden cualquier tipo de "heroísmo guerrero". Son elementos que tornan al individuo inamovible, cultor del pasado desde un conservadurismo que le viene bien al nacionalismo y al pensamiento burgués de la época. A este intelectual como a muchos otros en los últimos años republicanos, se puede atribuir la construcción de un discurso refundador de la nacionalidad desde la literatura, aun cuando cada cual en su posición este permeado de otras corrientes ideológicas.

Los letrados cubanos, fundamentalmente durante el siglo xix, dedicados a la invención de una tradición literaria cubana, propagadora de la idea de lo cubano como natural espontáneo, lejos de concebir la cubanidad como una "esencia", construyen un discurso variable, en torno a las exigencias e intereses de cada grupo en particular.

Muchas investigaciones, la mayoría realizadas en los últimos 10 años, se han encargado de trabajar teóricamente la cuestión nacional e ideológica en Cuba, desde concepciones prejuiciadas con el nacionalismo hasta partidarias atrincheradas del mismo. En todo caso, la cuestión de la formación nacional amerita reflexiones atentas, que no dejen de paso las peculiaridades de su historia. Cualquier acercamiento a estas temáticas debe tener en cuenta análisis comparativos $y$ determinantes en relación a los términos Patria y Nación, a la relevancia que ha tenido para la conciencia nacional cubana el hecho de tener como constante el asedio de los Estados Unidos, persistente en las concepciones alrededor de sí mismos. Otra cuestión importante en cuanto al estudio de la ideología en Cuba, la conformación nacional y la conciencia de la misma, es el debate a razón de las razas, la capacidad de autogobierno de los cubanos, la ética como escudo ante la intervención ajena, entre otras muchas determinantes latentes en la historia cubana.

El entendimiento del desarrollo de la ideología o las ideologías en Cuba es vital a la luz de la crisis del sistema capitalista y de la reformulación de nuestro socialismo. Comprender la historia de Cuba es tarea ardua, principalmente porque han de evitarse los cronologismos y los manualismos. Es una tarea que parece tornarse eternamente inacabada pero también podrá dar siempre frutos, al conocimiento como a la razón. 
BIBLIOGRAFÍA

LIBROS

Abreu Arcia, Alberto. Los juegos de escritura y reescritura de la historia. La Habana, Cuba: Fondo Editorial Casa de Las Américas, 2007.

Alfonso López, Félix J. Siete ensayos sobre historia y cultura en Cuba. Villa Clara, Cuba: Editorial Capiro, 2005.

Arcos, Jorge L. "Selección y prólogo". Ensayos. La Habana, Cuba: Editorial Letras Cubanas, 1999.

Díaz Quiñones, Arcadio. Cintio Vitier: la memoria integradora. San Juan, Puerto Rico: Editorial Sin Nombre, 1987.

Espinosa Domínguez, Carlos (comp.). José Lezama Lima. Revelaciones de mi fiel Habana. La Habana, Cuba: Ediciones Unión, 2010.

Guanche, Julio C. "La Constituyente de 1940 es una lección de madurez nacional. El periodo de 1935-1940 en la historia de Cuba. Entrevista con Berta Álvarez Martens". Imaginación contra la norma. La Habana, Cuba: Ediciones La Memoria-Centro Cultural Pablo de la Torriente Brau, 2004.

Guerra Sánchez, Ramiro. Guerra de los diez años 1868-1878. 2 volúmenes. La Habana, Cuba: Cultural, 1986.

Lezama Lima, José. "Conferencia sobre Manuel Zequeira y Manuel Justo de Rubalcaba". Fascinación de la memoria. Textos inéditos de José Lezama Lima. La Habana, Cuba: Editorial Letras Cubanas, 1993.

Lezama Lima, José. "Conferencia sobre Rafael Maria de Mendive y Tristán de Jesús Medina”. Fascinación de la memoria. Textos inéditos de José Lezama Lima. La Habana, Cuba: Editorial Letras Cubanas, 1993.

Lezama Lima, José. "El Romanticismo y el hecho americano". La expresión americana. La Habana, Cuba: Editorial Letras Cubanas, 2010.

Lezama Lima, José. "Palabras para los jóvenes". Imagen y posibilidad. La Habana, Cuba: Editorial Letras Cubanas, 1992.
Lezama Lima, José. Lezama disperso. La Habana, Cuba: Ediciones Unión, 2009.

Llorens, Irma. Nacionalismo y literatura. Constitución e institucionalización de la 'República de las letras Cubanas'. España: Asociación Española de Estudios Literarios Hispanoamericanos (AEELH), Ediciones de la Universidad de Lleida, 1998.

Mañach, Jorge. "Conferencias". La crisis de la alta cultura en Cuba. La Habana, Cuba: Imprenta y Papelería La Universal, 1925.

Mañach, Jorge. Historia y estilo. La Habana, Cuba: Editorial Minerva, 1944a.

Mañach, Jorge. Indagación del choteo. La Habana, Cuba: Editorial Libro Cubano, 1955. En: < http://www.revistacaliban. cu/clasico.php?numero $=9>$.

Mañach, Jorge. La nación y la formación histórica. Historia y Estilo. La Habana, Cuba: Editorial Minerva, 1944b.

Marinello, Juan. Creación y revolución. La Habana, Cuba: Ediciones UnEAC, 1973.

Marrero Fernández, Marilys. Con Cintio Vitier. De la libertad estética a la estética de la libertad. La Habana, Cuba: Editorial Ciencias Sociales, 2010.

Martí Pérez, José. Obras Completas. Tomo I. La Habana, Cuba: Editorial Ciencias Sociales, 1973.

Martínez Heredia, Fernando. Andando en la Historia. La Habana, Cuba: Instituto Cubano de Investigación Juan Marinello, 2009.

Martínez Heredia, Fernando. La Revolución del 30. Ensayos. La Habana, Cuba: Editorial Ciencias Sociales, 2007.

Mataix, Remedios. La escritura de lo posible. El sistema poético de José Lezama Lima. A. EeLH. España: Ediciones de la Universidad de Lleida, 2000.

Mella, Julio A. Glosas del pensamiento martiano. Documentos y artículos. Ciencias Sociales. La Habana, Cuba. 1975.

Rama, Ángel. La ciudad letrada. Hanover, Nueva Jersey: Ediciones del Norte, 1984.

Varela, Félix. Miscelánea filosófica. La Habana, Cuba: Universidad de la Habana, 1944. 
Vitier, Cintio (1958). Lo cubano en la poesía. La Habana, Cuba: Instituto Cubano del Libro, 1970.

Vitier, Cintio. Para llegar a orígenes. La Habana, Cuba: Editorial Letras Cubanas, 1994.

PUBLICACIONES PERIÓDICAS

Lezama Lima, José. "Secularidad de José Martí”. Revista Orígenes 33. Año X. Cuba, 1953.

Marinello, Juan. "Sobre el vanguardismo en Cuba y en la América Latina. Creación y Revolución. La Habana, Cuba. Ediciones Unión de Escritores y Artistas de CubaUNEAC, 1973: 65-80

Martínez Heredia, Fernando. "Palabras inaugurales"Revista Calibán. Cuba, abril-mayo-junio, 2010. En: < http:// www.revistacaliban.cu/articulo. php? numero=7\&article_id=76>.
Mataix, Remedios. "Para una teoría de la cultura: la expresión americana en José Lezama Lima”. Cuadernos Americanos. España: Asociación Española de Estudios Literarios Hispanoamericanos (AEELH), Ediciones de la Universidad de Lleida, 2000 .

TESIS

González Aróstegui, Mely. "La cultura de la resistencia en el pensamiento político de la intelectualidad cubana en las dos primeras décadas del siglo xx en Cuba". [Tesis de Doctorado en Ciencias Filosóficas]. Cuba, Universidad Central "Marta Abreu" de Las Villas, 2000.

Fecha de ingreso: 12/03/2013 Fecha de aprobación: 30/01/2014 
